Mots. Les langages du politique

\title{
Frères musulmans, frères féroces
}

\section{Maurice Tournier}

\section{OpenEdition}

Journals

Édition électronique

URL : https://journals.openedition.org/mots/1660

DOI : $10.4000 /$ mots. 1660

ISSN : 1960-6001

\section{Éditeur}

ENS Éditions

\section{Édition imprimée}

Date de publication : 1 novembre 2005

Pagination : 91-93

ISBN : 2-84788-084-4

ISSN : 0243-6450

\section{Référence électronique}

Maurice Tournier, "Frères musulmans, frères féroces », Mots. Les langages du politique [En ligne], 79 | 2005, mis en ligne le 28 mai 2008, consulté le 24 avril 2022. URL : http://journals.openedition.org/ mots/1660 ; DOl : https://doi.org/10.4000/mots.1660 


\title{
Comptes rendus
}

\author{
Frères musulmans, frères féroces. \\ Voyage dans l'enfer du discours islamiste \\ Latifa Ben Mansour ${ }^{1}$ \\ 2002, Paris, Ramsay, 263 p.
}

Les frères féroces sont à la fois un document et un témoignage. Un document sur le discours dit «islamiste» en Algérie, dont il faut savoir écouter la radicalité totalitaire. Un témoignage sur l'écrivaine Latifa Ben Mansour, dont il faut aussi savoir écouter la souffrance et la révolte.

Il est indispensable, avant d'en oser dire un mot, de rencontrer la parole d'un adversaire, ne serait-ce que pour connaitre ses raisons de se vouloir adverse. Le discours islamiste, pour ce qui concerne l'Algérie, a été ouvertement tenu, clamé, imprimé, diffusé publiquement ou sous le manteau. Le premier travail de L. Ben Mansour fut d'en collecter cassettes et articles puis, avec ténacité, de le décrypter et traduire en français, au plus près des enregistrements. Au croisement de compétences multiples que peu d'entre nous possèdent en même temps : linguiste arabisante titulaire d'un doctorat d'État, grande écrivaine de langue française, musulmane versée dans l'exégèse coranique, héritière des traditions andalouses, psychanalyste freudienne et lacanienne... II faut lire, derrière ses coups de sang et ses emportements verbaux, sa rage de voir sa culture issue d'appartenances multiples - toute avancée culturelle n'opère-t-elle pas par métissage? - et l'effort vers la démocratie, le respect de l'Homme, le message tolérant du Prophète, bafoués ou pervertis.

À sa suite, on doit se rappeler qu'Hitler avait tout découvert de ses projets dans Mein Kampf, et la destruction de la France, et l'hégémonisme nazi, et sa « race » purifiée et triomphante, et l'anéantissement des juifs et autres gêneurs ou boucs émissaires. Un fou, disait-on... Goebbels avait tracé le plus cynique des programmes de propagande. Un Machiavel au petit pied, semblait-il. Tout cela n'est que cinéma, intimidation, fausses nouvelles, croyait-on. Et nous

1. L'ouvrage dessine l'arrière-plan tragique dans lequel vient s'inscrire son dernier roman, L'année de l'éclipse, 2001, Paris, Calmann-Lévy. Deux romans ayant pour cadre l'Algérie ont précédé ces écrits, Le Chant du lys et du basilic, 1990, Paris, Lattès, et La Prière de la peur, 1997, Paris, La Différence. Une suite de Frères musulmans, frères féroces a été récemment publiée sous le titre Les mensonges des intégristes, 2004, Paris, Le Serpent à plumes. 
avions devant les yeux leur livre ouvert sur des credos démentiels... Un autre livre s'est écrit en Algérie pendant quinze ans. Pour le comprendre, il faut connaitre aujourd'hui non pas simplement le Coran - car il ne dit rien sur un terrorisme qu'il est très loin de prôner - mais la parole qui a osé se revendiquer de lui, dans les mosquées et sur les marchés d’Alger, dans les médias algériens, entre 1989 - date de la légalisation du Front islamique du Salut - et 1991 - date de l'interdiction du FIS. En confrontant le discours nazi et celui des intégristes radicaux, L. Ben Mansour met au jour une ressemblance qu'il faut bien appeler «totalitarisme» : "Nous sommes un peuple musulman, hommes et femmes, qui ont fait des sacrifices pour la religion musulmane pour éradiquer les mécréants et les impies. ${ }^{2}$

Nous vivons aujourd'hui une époque de grands cynismes : discours du profit, discours du fanatisme, l'un et l'autre habillés de religion et de morale. Écoutons l'un et l'autre ; ils se répondent. Les sermons moraux, dits " occidentaux ", ne nous bernent plus, à cause de leur naïveté apparente («Pourquoi tant de haine contre nous? Nous sommes bons ", s'étonnait George W. Bush). Chercheurs de stéréotypes, nous avons commencé à faire un sort à leur phraséologie pseudo-chrétienne. Il ne faut pas que, de leur côté, des prêches qui se disent carrément anti-occidentaux, anti-droits de l'homme, anti-laïques, se banalisent en se parant eux aussi de références divines. Comme les premiers, ils sont à décrypter, comme tout discours politique qui, par définition, sert à prendre ou à garder le pouvoir. Tel est notre devoir de citoyen, pense L. Ben Mansour : avant tout, entrer dans le projet de l'adversaire, à la rencontre de ses justifications et de sa rhétorique incantatoire pour en montrer la perversité, la férocité. Il ne suffit pas de dire : ils sont fous. En interrogeant leurs textes, elle montre pourquoi, comment et jusqu'à quel point leur folie religieuse risque de se révéler dangereuse, contagieuse, laissant à d'autres - historiens, sociologues - la recherche des actants souterrains qui les utilisent.

Sont-ils d'ailleurs religieux, ces prêches? La religion en soi a été rarement, au cours de l'histoire, la cause initiale d'une vague meurtrière. Elle a toujours servi d'outil idéologique au service de volontés de puissance. C'était déjà le cas au temps médiéval de nos Croisades, qui ont réussi jusqu'à faire bouger le petit peuple vers son propre massacre. L'expansionnisme occidental, armé lui, pillant et brulant la grande Constantinople chrétienne, n'a eu que faire des chrétiens et des juifs orientaux. Les lieux saints avaient bon dos. Les croix fourmillaient sur les poitrines, et des cyniques en ont profité pour se tailler là-bas des royaumes à coups d'épée. Il est évident que les « intégristes » radicaux d'Algérie et d'ailleurs tiennent un discours de croisade. Leur machiavélisme se revêt

2. «Ceux qui continuent d'affirmer que ce sont les démocrates qui ont utilisé le terme d'éradication peuvent constater que les intégristes algériens étaient les premiers à en faire usage. » (note de L. Ben Mansour, p. 129) 
d'un jihâd belliqueux ${ }^{3}$. La charia - qui n'est qu'une adaptation juridique de certains préceptes du Coran choisis pour une époque donnée - devient, dans leur discours, Loi extra-temporelle, d'origine divine, donc irréfutable et intangible, à imposer à quelque époque que ce soit ${ }^{4}$ et à qui que ce soit : «Le FIS est venu pour réveiller et sauver la Communauté, pour sauver le monde » (Abbassi Madani). Cet achronisme affiché fait la racine première de leur phraséologie. Et en avant pour tout justifier, y compris la destruction de toute démocratie, le refus de la Constitution, du qanoun', l'intolérance vis-à-vis des autres, le meurtre en petit et en grand, l'embrigadement idéologique ${ }^{6}$, l'esclavage de la femme l $^{7}$ De là vient le GIA, « cet enfant monstrueux du FIS ». L. Ben Mansour le prouve, textes à l'appui. Le pire serait de répondre avec les mêmes incantations. Apprendre à écouter la parole d'un adversaire sans généraliser son modèle à toute l'islamité, c'est ce qu'essaie de faire L. Ben Mansour, malgré la douleur de ses déchirures et ses propres détestations, si passionnément exprimées, témoin qu'elle est, authentiquement, de la tragédie subie pendant quinze ans par ses frères et sœurs d’Algérie. "Il faut arrêter de globaliser », écrit-elle.

La comprendre, elle? Eh bien, la lire, dans l'interprétation savante et critique de textes qu'elle a fini par connaitre par cœur, jusqu'à la nausée, et avec lesquels elle ne réussit à prendre des distances que grâce à l'analyse des mots et à l'explication psychanalytique. On doit reconnaitre, en suivant sa démarche d'analyste, qu'elle a fait tout au long de sa présentation des prêches «intégristes » un énorme effort personnel pour éclairer, de l'intérieur d'un discours, une vérité inhumaine.

Maurice Tournier

\section{Pourquoi sommes-nous en guerre?}

Norman Mailer

traduit de l'anglais (Why are we at war ?) par Bernard Cohen, 2003, Paris, Denoël, 113 p.

Depuis Les Nus et les Morts jusqu'au Combat du siècle, Norman Mailer ne cesse de s'interroger sur la guerre, l’impérialisme économique et politique, sur leurs raisons et leurs justifications. Il y a 35 ans paraissait son courageux

3. Voir l'article de L. Ben Mansour, 2002, «L'appel au soulèvement et à la révolution par les intégristes algériens », dans Mots. Les Langages du politique, n 69, juillet, p. 81-93. "La guerre de Dieu est pour nous allumée », disait Abbassi Madani en novembre 1989 (cité par L. Ben Mansour, p. 116).

4. «Notre but stratégique ultime est d'instaurer le califat islamique sur la terre.» (Ali Benhadj, al-Watan al-arabi, 27 juillet 1990, cité p. 128)

5. "Le qanoun ne doit pas contredire la Charia... » (cité p. 202)

6. «La femme doit élever son fils et le sacrifier dans la voie d’Allah. »(Ali Benhadj, cité p. 217)

7. «La femme est une productrice d’hommes /.../ Un état islamique doit être dirigé par un mâle. 